\title{
Analysis of the Organic Matter in Oil Shales Distributed in Korea
}

\author{
Moon Yul Yang, Chi Wan Jeon, Myoung Kee Yang*, Sang Hak Lee**, Hisanobu Wakita*** \\ Laboratory of Chemical Analysis, Korea Institute of Geology, Mining and Materials, Taedok \\ Science Town, Taejon, Korea \\ *Technical Service Center for Engineering Plastics, Tongyang Nylon Co. Ltd, Anyang, Kynngi-do, Korea \\ **Department of Chemistry, Kynmgpook National University, Taegu, 702-701, Korea \\ ***Department of Chemistry, Faculty of Science, Fukuoka University, Nanakuma, Fukuoka 814-01, Japan
}

\begin{abstract}
The organic matter in source rocks and oil shales distributed in the southeastern and southwestern parts of the Korean peninsular has been analyzed. A mixture of benzene, acetone and methanol was used to extract bitumen by Soxhlet extraction method. The extractable organic matter was separated into aliphatic hydrocarbons, aromatic hydrocarbons, and asphaltene by preparative thin layer chromatography. By urea adduction method, aliphatic hydrocarbons were separated into linear aliphatic hydrocarbons and cyclic or branched aliphatic hydrocarbons. The aliphatic hydrocarbons were analyzed by GC/FID and GC/MS. The gas chromatograms for linear aliphatic hydrocarbons showed the distribution of $\mathrm{C}_{12}-\mathrm{C}_{35}$ compounds. Generally, the odd number hydrocarbons were detected more than the even number hydrocarbons. From the total ion chromatograms and mass spectra of cyclic and branched aliphatic hydrocarbons, several compounds including 1-methylpropyl-cyclohexane were identified.
\end{abstract}

Keywords Soxhlet extraction, bitumen, preparative thin layer chromatography, aliphatic hydrocarbons, oil shale

Oil shales is one of the promising sources for the production of synthetic liquid fuels in the next century. Even though there is actually no geological or chemical definition of oil shale, any shallow rock yielding oil in commercial amount upon pyrolysis is considered to be an oil shale. The quality of oil shale is generally evaluated by the amount and types of kerogen and bitumen, and the evolutionary stages of kerogen which is commonly referred to as maturity. ${ }^{2}$ Bitumen is termed for the naturally occurring hydrocarbon substances such as oil, asphalt and ozocerite (mineral wax), and the organic solvent extracts from various sedimentary rocks, soils, coal and oil shale. Hydrocarbons are the main constituents of naturally occurring bitumen. It is widely accepted from geological and chemical evidence that hydrocarbons result from alteration of organic matter within sedimentary rocks under the influence of temperature and pressure. ${ }^{1}$ The occurrence of hydrocarbons and related substances is known from a wide range of living organisms, many of which have been found in sediments and in crude oils. Numerous types of hydrocarbons or substances with a similar carbon skeleton have been traced from the living organisms into sediments. ${ }^{3-5}$ Source potential for hydrocarbons is dependent on the type and quantity of the organic matter, whereas the generation potential for hydrocarbon is controlled by the extent of thermal evolution of organic matter. ${ }^{4}$ Therefore, the prerequisite of source rock evaluation is the improved analytical techniques employed to determine the composition in detail. Frequently used analytical methods have been pyrolysis, ${ }^{6 \cdots 11}$ total organic carbon determination, ${ }^{1,12}$ organic petrography, ${ }^{1,4,13}$ optical analysis, ${ }^{14}$ and various organic geochemical analyses. 15,16

In the present study, we have investigated the chemical composition and organic geochemical characteristics of the oil shale and source rock samples collected from the southwestern and southeastern parts of the Korean peninsular. The main facet of this report concerns the methods for the extraction of organic matter, separation of extracts into different groups and identification of individual compounds. Bitumen was extracted by a soxhlet extraction method and the extracts were separated into saturated hydrocarbons, aromatics and asphaltene by preparative thin layer chromatography (prep-TLC). The n-alkanes were separated by urea adduction method and the distribution of n-alkanes for each sample was investigated by gas chromatography. The branched and cyclic hydrocarbons were characterized by gas chromatography mass spectrometry and some individual compounds were identified. 


\section{Experimental}

Samples

Three petroleum source rock samples were collected from the Yongil bay tertiary strata distributed in the southeastern part of Korea (Kyungpook Province): sample A (Uhyun-Dong, Pohang-Si); sample B (Yongheung-Dong, Pohang); sample C (Hakjon-Dong, Yonil-Eub). Samples D and E were collected from the southwestern part of Korea (Chunnam Province): sample D (Uhangpo); sample E (Sinseongri). The E sample was taken from the 33.1 $m$ section of the Sinseongri-1 well.

\section{Materials and reagents}

The sources of the reagents were as follows: magnesium sulfate (GR), calcium chloride (GR), benzene(GR) and hexane (GR) from Junsei (Tokyo, Japan); silica gel and TLC plate from Merck (Darmstadt, Germany); concentrated hydrochloric acid and berberine sulfate (neutral sulfate) from Sigma (St. Louis, MO, USA); chloroform (HPLC grade) and cupric sulfate from J. T. Baker (Phillipsburg, NJ, USA); methanol (LC grade) from Fluka (Buchs, Switzerland); cyclohexane (EP) from Yakuri (Osaka, Japan). All other chemicals were of analytical reagent grade. Thimble filters $(23 \times 90 \mathrm{~mm})$ used for Soxhlet extraction were purchased from Whatman (Maidstone, England).

\section{Instrumentation}

A Yanaco Model MT-2 (Kyoto, Japan) was used for organic elemental analyses with carrier gas of high purity helium at a flow rate of $180 \mathrm{~mL} / \mathrm{min}$ and temperature of $850-900{ }^{\circ} \mathrm{C}$. The apparatus used for prep-TLC was a Model Linomat III (CAMAG, Muttenz, Switzerland). A Hewlett-Packard (HP) 5890 series II gas chromatograph was used with a flame ionization detector, a HP 7673A autosampler and a HP 5895A Chemstation for GC analysis. GC/MS analyses were carried out on a Varian Model 3700 GC (Varian, Australia) equipped with a Varian MAT 212 mass spectrometer. The instrumental components and operating conditions used in this work are summarized in Table 1 . These operating conditions were selected after the optimization of each parameter.

\section{Analytical method}

The schematic outline of the analytical procedures used in this study is given in Fig. 1. The raw samples were crushed using a jaw crusher (DFCC, 2P2P5) and were then pulverized with a pulverizer (BICO, MFD, UD 32) to pass a 140 mesh screen. The resulting powder was dried at $80{ }^{\circ} \mathrm{C}$ over anhydrous $\mathrm{MgSO}_{4}$ in an oven for $24 \mathrm{~h}$, re-dried over anhydrous $\mathrm{CaCl}_{2}$ at room temperature under reduced pressure ( 0.2 torr) in a vacuum oven, and stored in a
Table 1 Instrument components and operating conditions for $\mathrm{GC}$ and $\mathrm{GC} / \mathrm{MS}$

\begin{tabular}{|c|c|}
\hline $\mathrm{GC}$ & HP $5890 \mathrm{I}$ \\
\hline & HP 7673A autosampler \\
\hline Column & $\begin{array}{l}\text { HP 5895A Chemstation } \\
\text { capillary }^{\mathrm{a}}\end{array}$ \\
\hline Oven Temp & $\begin{array}{l}30-150^{\circ} \mathrm{C}, 15^{\circ} \mathrm{C} / \mathrm{min} \\
150-290^{\circ} \mathrm{C}, 3{ }^{\circ} \mathrm{C} / \mathrm{min} \\
10 \text {-min hold }\end{array}$ \\
\hline \multicolumn{2}{|l|}{ Injection } \\
\hline Type & split (30:1) \\
\hline Temp & $270^{\circ} \mathrm{C}$ \\
\hline \multicolumn{2}{|l|}{ Detector } \\
\hline Type & FID \\
\hline Temp & $300{ }^{\circ} \mathrm{C}$ \\
\hline \multicolumn{2}{|l|}{ Flow rate } \\
\hline Column & $2 \mathrm{~mL} / \mathrm{min}\left(\mathrm{N}_{2}\right)$ \\
\hline Make-up gas & $23 \mathrm{~mL} / \mathrm{min}\left(\mathrm{N}_{2}\right)$ \\
\hline $\mathrm{H}_{2}$ & $42 \mathrm{~mL} / \mathrm{min}$ \\
\hline Air & $350 \mathrm{~mL} / \mathrm{min}$ \\
\hline \multicolumn{2}{|l|}{ GC-MS } \\
\hline GC & Varian 3700 \\
\hline Column & capillary $^{c}$ \\
\hline \multicolumn{2}{|l|}{ Injection } \\
\hline Type & Open \\
\hline Temp & $25^{\circ} \mathrm{C}$ \\
\hline MS & Varian MAT 212 \\
\hline Ionization & electron impact \\
\hline Electron energy & $70 \mathrm{eV}$ \\
\hline Emission current & $1 \mathrm{~mA}$ \\
\hline Source temp & $200{ }^{\circ} \mathrm{C}$ \\
\hline
\end{tabular}

a. Fused silica capillary column (SE-30, $0.25 \mathrm{~mm}$ id $\times 30$ $\mathrm{m}, 0.25 \mu \mathrm{m}$ film thickness). b. These conditions are also used in GC-MS. c. Fused silica capillary column (HP-1, $0.53 \mathrm{~mm}$ id $\times 5 \mathrm{~m}$ ).

\section{desiccator.}

The extraction of organic matter from sample $(50 \mathrm{~g})$ was performed in a Soxhlet apparatus with a $250 \mathrm{~mL}$ mixture of benzene, acetone and methanol (50:25:25, $\mathrm{v} / \mathrm{v}$ ) for $72 \mathrm{~h}$. The solvent was removed by rotary evaporation at room temperature and the resulting extractable organic matter (EOM) was weighed.

For prep-TLC, a Merk TLC plate coated with 2 $\mathrm{mm}$ silica gel without fluorescence indicator was used. The plate was prewashed in two directions using a mixture of chloroform/methanol $(1: 1, v / v)$ and ethylacetate respectively. Prior to use the plate was activated for $30 \mathrm{~min}$ at $110{ }^{\circ} \mathrm{C}$. The extract was spotted on to the plate by using a CAMAG apparatus. Elution was carried out using cyclohexane for $2 \mathrm{~h}$. Visualization was performed using $0.5 \%$ methanol solution of berberine sulfate and examination of the bands with UV lamp. The 


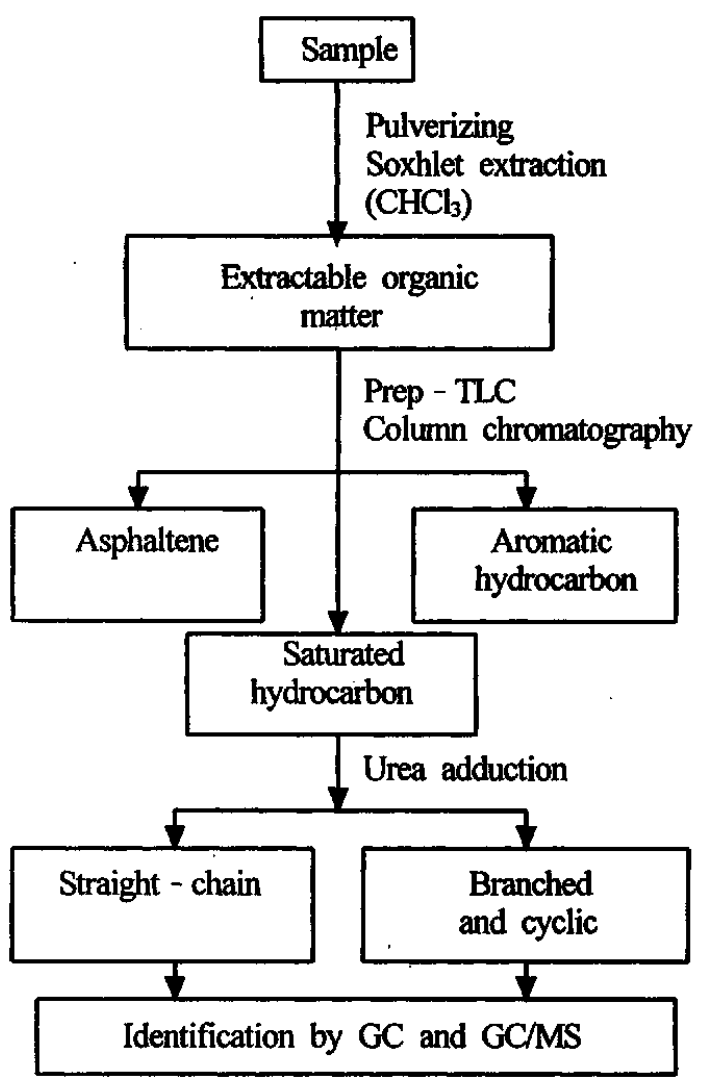

Fig. 1 Schematic outline of the experimental procedures to analyze extractable organic matter in sedimentary rocks.

resulting bands were then removed. The aliphatic and aromatic bands were extracted with chloroform. The asphaltene band was extracted with chloroform and methanol in sequence. Elemental sulfur was removed from the fractions of aliphatic compounds by precipitating in the form of $\mathrm{CuSO}_{4}{ }^{17}$

\section{Results and Discussion}

\section{Extractable organic matter}

The analytical results of total organic carbon (TOC) and extractable organic matter (EOM) are summarized in Table 2. The contents of TOC ranged from $1.18-1.25 \%$ for all of the samples except sample B. The EOM content of sample B was also lower than those of the rest of the samples. In general, samples collected from the southeastern part of Korea (D and E) gave higher contents of EOM and bitumen ratio than samples collected from the southwestern part of Korea. The differences in bitumen ratio between the samples of the two different area may suggest different degree of maturity and/or different source input.

The results of prep-TLC are summarized in Table
Table 2 Total organic carbon (TOC) and extractable organic matter (EOM)

\begin{tabular}{cccc}
\hline Sample & TOC & EOM & Bitumen ratio $^{{ }^{a}}$ \\
\hline A & 1.18 & 0.20 & 17 \\
B & 0.35 & 0.08 & 20 \\
C & 1.23 & 0.58 & 47 \\
D & 1.20 & 0.59 & 49 \\
E & 1.25 & 0.45 & 36 \\
\hline
\end{tabular}

a. Ratio of EOM/TOC.

Table 3 Summary of fractions separated by preparative thin layer chromatography from the extractable organic matter

\begin{tabular}{ccccc}
\hline Sample & $\begin{array}{c}\text { SAT }^{\mathrm{a}} \\
(\%)\end{array}$ & $\begin{array}{c}\text { ARO }^{\mathrm{b}} \\
(\%)\end{array}$ & $\begin{array}{c}\text { ASP }^{\mathrm{c}} \\
(\%)\end{array}$ & Ratio (SAT/ASP) \\
\hline A & 68.9 & 8.5 & 22.5 & 3.1 \\
B & 45.5 & 15.7 & 38.8 & 1.5 \\
C & 52.0 & 17.3 & 30.5 & 1.7 \\
D & 80.7 & 8.0 & 11.3 & 7.1 \\
E & 73.9 & 11.4 & 14.8 & 5.0 \\
\hline
\end{tabular}

a. Saturated. b. Aromatics. c. Asphaltene.

Table 4 Summary of gas chromatographic analyses of n-alkane compounds in the saturated hydrocarbon fraction

\begin{tabular}{cclc}
\hline Sample & Distribution & \multicolumn{1}{c}{ Maxima } & Ratio $^{\mathrm{a}}$ \\
\hline $\mathrm{A}$ & $\mathrm{C}_{11}-\mathrm{C}_{27}$ & $\mathrm{C}_{17}$ & 0.74 \\
$\mathrm{~B}$ & $\mathrm{C}_{12}-\mathrm{C}_{27}$ & $\mathrm{C}_{15}, \mathrm{C}_{17}, \mathrm{C}_{19}$ & 0.68 \\
$\mathrm{C}$ & $\mathrm{C}_{11}-\mathrm{C}_{28}$ & $\mathrm{C}_{15}, \mathrm{C}_{17}$ & 1.9 \\
$\mathrm{D}$ & $\mathrm{C}_{14}-\mathrm{C}_{33}$ & $\mathrm{C}_{21}, \mathrm{C}_{23}$ & 0.32 \\
$\mathrm{E}$ & $\mathrm{C}_{13}-\mathrm{C}_{34}$ & $\mathrm{C}_{21}, \mathrm{C}_{22}, \mathrm{C}_{23}$ & 0.28 \\
\hline
\end{tabular}

a. Ratio of branched and cyclic hydrocarbons/n-alkanes.

3. The contents of saturated hydrocarbon (SAT) and the ratio of SAT to asphaltene for $D$ and $E$ samples were generally higher than A, B and C samples. It is interesting to note that sample $\mathrm{C}$ gave relatively higher contents of aromatic compounds.

\section{Analysis of saturated hydrocarbons}

The separation of straight-chain alkanes from the saturated hydrocarbon fraction was performed by using the urea adduction method. ${ }^{18}$ The GC chromatograms recorded by using fused silica capillary column were well-shaped and similar in shape for all of the samples, with the distribution of $\mathrm{n}$-alkane in the range of approximately $\mathrm{C}_{11}-\mathrm{C}_{34}$ and maxima at $\mathrm{C}_{15}-\mathrm{C}_{23}$. The Bimodal n-alkane distribution reported for the sample collected from the 
Table 5 Branched and cyclic hydrocarbons in the saturated hydrocarbon fraction identified by GC/MS for sample C

\begin{tabular}{cl}
\hline RT, min & \multicolumn{1}{c}{ Compound (Characteristic ions) } \\
\hline 6.79 & (1-Methylpropyl)-cyclohexane $(55,83,179)$ \\
7.00 & 2,9-Dimethyldecane $(43,57,99,170)$ \\
7.85 & 6-Ethyl-2-methyldecane $(43,57,71,113)$ \\
8.49 & 2,3,7-Trimethyldecane $(43,57,97,127)$ \\
8.85 & 2,6,10-Trimethyldodecane $(57,71,141,196)$ \\
8.94 & 2-Cyclohexyloctane $(41,111,141)$ \\
9.06 & 5,8-Diethyldodecane $(41,111,141)$ \\
9.69 & 3-Methyl-8-propyldodecane $(57,71,119,246)$ \\
10.51 & 3-Methylhexadecane $(57,85,126)$ \\
10.64 & 4-Methylheptadecane $(43,154,179)$ \\
11.08 & 1-Nonadecene (41,97,207) \\
11.58 & 2-Methylhexadecane $(43,71,183,193)$ \\
12.79 & 1-Octadecane $(57,85,183,207)$ \\
12.90 & 2-Methylnonadecane $(43,71,179)$ \\
13.22 & 3-Methyleicosane $(43,83,119)$ \\
14.16 & (1-Propylheptadecyl)-cyclohexane $(55,83,238)$ \\
16.40 & (1-Hexyltetradecyl)-cyclohexane $(41,83,165,196)$ \\
17.42 & 9-Cyclohexyleicosane $(57,71,239,253)$ \\
17.96 & 17-Pentatriacontene $(43,71,273)$ \\
\hline
\end{tabular}

base of the cliff at Port Mulgrove, North Yorkshire was not observed for all of the samples studied in the present work. ${ }^{19}$ In addition, for all of the samples, the odd-carbon-number predominance was observed in n-alkanes of medium molecular weight $\left(\mathrm{C}_{15}-\mathrm{C}_{25}\right)$. The summary of $\mathrm{n}$-alkane distribution and its maxima for each sample is represented in Table 4. For the $A, B$ and $C$ samples, the maxima abundances observed at $\mathrm{C}_{15}-\mathrm{C}_{19}$ indicate that the origin for the organic matters in these samples is a lower plant such as cyanobacteria and algae. The D and $\mathrm{E}$ samples gave similar gas chromatographic results in terms of the n-alkane distribution and the most abundant compounds. Maxima in abundance at $\mathrm{C}_{21}-\mathrm{C}_{23}$ for these samples suggest that the organic matters in this sample originate from lower land plants such as mosses. The ratios of branched and cyclic hydrocarbons to n-alkanes are also given in Table 4. Of importance to note is that the Sample C is unique in this ratio within the samples studied in the present work. The exceptionally high concentration of branched-alkane compound in this sample may be explained as due to the process of biodegradation. The n-alkanes are known to be depleted in the oils when certain bacteria contacts oils. ${ }^{1,4}$

The analyses of branched and cyclic hydrocartons were performed by using GC/MS. Identification of compounds was accomplished by comparison of obtained spectra with archived and literature spectra, and, in most cases, was verified by comparison with known compounds. Selected ion monitoring was also carried out by monitoring different $\mathrm{m} / \mathrm{z}$ values to characterize each compound. The GC/MS results for sample $\mathrm{C}$ is summarized in Table 5. To be noted here is that the compounds identified in the present study are not complete. The detailed structural identification of iso-alkanes, aromatics, asphaltenes and kerogen is being studied in this laboratory.

\section{References}

1. B. Tissot and D. H. Welte, "Petroleum formation and Occurrence", Springer-Verlag, Berlin, 1978.

2. N. V. Dung, Fuel, 68, 1570 (1989).

3. J. M. Moldowan, J. Dahl, M. A. McCaffrey, W. J. Smith and J. C. Fetzer, Energy \& Fuel, 9, 155 (1995).

4. J. M. Moldowan, P. Albrecht and R. P. Philip (eds.), "Biological Markers in Sediment and Petroleum", Prentice Hall, Englewood Cliffs, NJ, 1992.

5. K. E. Peters and J. M. Moldowan, "The Biomaker Guide", Prentice Hall, Englewood Cliffs, NJ, 1993.

6. K. Kuroda, A. Suzuki, M. Kato and K. Imai, $J$. Anal. Appl. Pyrolysis, 34, 1 (1995).

7. T. A. Centeno, J. J. Pis, J. A. Pajares and A. B. Fuertes, J. Anal. Appl. Pyrolysis, 34, 13 (1995).

8. S. H. Lee and M. Y. Yang, J. of Korean Ind. \& Eng. Chemistry, 2, 185 (1991).

9. M. Y. Yang, S. H. Lee and J. T. Park, J. Korean Chem. Soc., 35, 737 (1991).

10. Y. O. Son, D. Y. Song, S. H. Lee, C. H. Eum and J. T. Park, Research Report: No. KR-88-3A1; KIER, Korea, 1988.

11. M. Y. Yang, Ph. D. Dissertation, Fukuoka University, 1993.

12. J. M. Hunt, "Petroleum Geochemistry and Geology", W. H. Freeman, San Francisco, 1979.

13. W. G. Dow, J. Geochem. Explor., 7, 79 (1977).

14. O. T. Tuo and E. E. Etuk, J. Geochem. Explor., 37, 285 (1990).

15. D. H. Welte, M. A. Yukler, M. Radke and D. Leythaeuser, in "Origin and Chemistry of Petroleum", eds. A. Gordon and J. J. Zuckermann, Pergamon Press, Oxford, 1981.

16. A. A. K. Mohammed, Analyst [London], 110, 1477 (1985).

17. M. Blumer, Anal. Chem., 29, 1039 (1957).

18. S. Hala, M. Kuras and M. Popl, in "Comprehensive Analytical Chemistry", Vol. XIII, Part A, ed. G. Svehla, p. 227, Elsevier/North Holland, Inc., New York, 1981.

19. S. R. Palmer, A. F. Gaines and A. W. P. Jarvie Fuel, 68, 1234 (1989). 